\title{
Disculpe, ¿qué dijo? El lenguaje en la práctica docente del arquitecto
}

Jorge Carlos Parga Ramírez y Alejandra Torres Landa López

\section{Introducción}

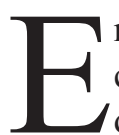
n la mayoría de las instituciones de educación superior (IES) que imparten la carreras de Arquitectura, el modelo educativo está basado en la Escuela de Bellas Artes, ${ }^{1}$ es decir, que los planes de estudio tienen como eje rector los talleres de diseño que deben servir como catalizadores, ya que generalmente en ellos se trabaja con base en el método de aprendizaje basado en problemas (ABP), en los que los estudiantes deben integrar conocimientos y habilidades adquiridas durante la carrera hasta ese momento. Como lo señala el Modelo Educativo Institucional (MEI) de la Universidad Autónoma de Aguascalientes (UAA), una dimensión de la práctica docente es la evaluación de los aprendizajes, desde su diagnóstico, pasando por la procesual, hasta la sumativa (UAA, 2015).

En los talleres antes mencionados, la evaluación procesual se lleva a cabo mediante la crítica, estrategia de enseñanza y aprendizaje que utiliza diferentes modalidades de comunicación: verbal, escrita, gráfica y/o no verbal; de tal manera que la comunicación es fundamental para que se dé una buena crítica; $y$, a pesar de que antes de revisar una propuesta de diseño arquitectónico, los profesores toman en cuenta las condiciones y los métodos para la misma y procuran que la retroalimentación sea la adecuada para lograr el aprendizaje (Oh, Ishizaki, Gross, \& Yi-Luen Do, 2013), pareciera que el lenguaje verbal que se utiliza, no permite que el mensaje sea interpretado adecuadamente por el receptor, en este caso

1 La Escuela de Bellas (École des Beaux-Arts) fundada en 1803 en Francia formó a los arquitectos franceses del siglo xIx y tuvo gran influencia en gran parte del mundo. La enseñanza tenía como base las raíces de la arquitectura clásica y neoclásica (Wilkinson, 2014). el estudiante; lenguaje que, como se describe en este artículo, ${ }^{2}$ es reflejo del mundo posmoderno, actúa e impide la vinculación con la vida cotidiana.

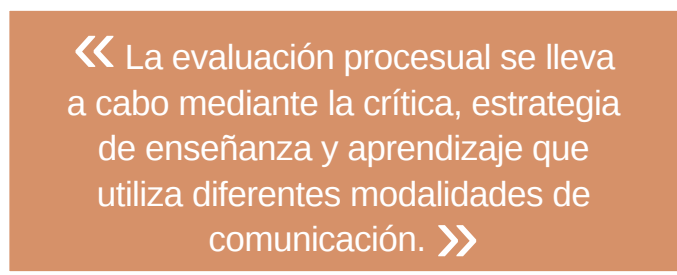

\section{La posmodernidad y la comunicación}

Al parecer, la principal razón de esta brecha entre la persona que emite el mensaje (profesor) y la que lo recibe (estudiante), es en muchas ocasiones generacional, con lenguajes diferentes por la desigualdad de preparación que se tiene y las distintas experiencias que se han vivido, entre otras, todas marcadas por las características de la sociedad del siglo XXI.

Hoy en día se vive con los avances de las tecnologías de la información y comunicación (TIC) en un mundo ahora denominado "posmoderno". TIC que producen cambios en la mayoría de las actividades de la sociedad, principalmente en la manera en que se comunican, y gracias a las cuales la comunicación es masiva y sus contenidos menos importantes que la forma de transmitirla, incluso hasta llevarla a un nivel de "espectáculo".

De manera distintiva, el mundo posmoderno niega el método científico como único referente de verdad absoluta como se tenía concebido en el mundo moderno, donde el saber científico

\footnotetext{
2 Este artículo surge a partir del primer acercamiento del problema de la investigación PIA16-1N: La flexibilidad en el diseño arquitectónico. Nuevas tendencias en el proceso de diseño.
} 
establecía unilateralmente una clase de discurso, obviamente apoyado en el lenguaje fonológico, lingüístico, cibernético, matemático/algebraico, informático, entre otros, el cual afecta o limita los propios trabajos de investigación y la difusión del conocimiento obtenido de los mismos.

Al respecto, François Lyotard ${ }^{3}$ señala que las nuevas investigaciones deben sujetarse a utilizar la terminología propia del gremio intelectual de su disciplina. Por ello, los "grandes" científicos inventan y proponen un "nuevo lenguaje" (jerga científica), que los aspirantes a la investigación deberán aprender para tener algún tipo de aceptación de resultados en algún estudio $\mathrm{y}$, entonces, poder ser considerado como "saber". Al utilizar este lenguaje hay que tomar en cuenta: 1) que las reglas no tienen legitimación en ellas mismas, sino que forman parte de un contrato explícito o implícito entre los jugadores; 2) a falta de reglas no hay juego, o un cambio en ellas modifica la naturaleza de éste; y 3) todo enunciado puede ser considerado como una «jugada» (Lyotard, 1987).

\section{El lenguaje, base de la evaluación procesual en los talleres de diseño arquitectónico}

Sin embargo, la confusión y la ambigüedad no quedan únicamente en la ciencia, ya que se filtra a diferentes disciplinas, como es la del diseño. Por ejemplo, si alguien ha platicado con un arquitecto o ha entrado a un taller de diseño arquitectónico, pareciera que se transporta a otro país, porque se oye como si se estuviera hablando en otro idioma; es difícil entender lo que se está diciendo, no comprende el "contrato explícito entre los jugadores", es así que se escuchan argumentos por parte de algún profesor diciéndole a un estudiante:-Hay que interrogar a la potencialidad hermenéutica de las condiciones de frontera de la trama urbana, ya que es la clave para intervenir en la morfología de la ciudad. La naturaleza fenomenológica de un edificio y su barrio está ataviada con actos lúdicos de horizontalidad-; incluso el idioma inglés tiene su propia denominación a esta forma de hablar: $A r$ chispeak, Archibabble o Talkitecture (Richards, 2014), en español, ¿podríamos denominarle arqui-

3 François Lyotard (1924-1998). Filósofo francés y uno de los principales autores que aborda el tema de la posmodernidad. lenguaje, arquiblabla o hablartectura?

Siendo así, los estudiantes que por su "falta de conocimiento en las reglas" no puedan participar en el "juego", serán sancionados o marginados, al incurrir en una interpretación espontánea por su parte, que les modifique "la naturaleza del juego". Este juego podría, en algunos casos, considerarse como una moda o "esnobismo" por parte de los arquitectos y/o profesores de esta disciplina, al parecer reflejo de la posmodernidad en la que se vive, ya que, como se señaló anteriormente, el conocimiento y su método tienen un lenguaje construido para una elite, tal es el caso de la metodología o apropiadamente, método impartido en la carrera de Arquitectura de la UAA, donde los enunciados de esa -mal denominada- "metodología", son "observación explícita" para que pertenezcan al lenguaje de los expertos, los sapiens (Lyotard, 1999).

Más aún, el método que se utiliza en los talleres de diseño arquitectónico de la UAA para guiar el proceso creativo de los estudiantes basado en el método científico, acepta y postula que el diseño arquitectónico es una disciplina científica; sin embargo, esta postura responde a principios de la época moderna, en la que se concebía como única verdad el conocimiento adquirido bajo un paradigma positivista, ${ }^{4}$ por lo cual, está lleno de conceptos y terminología científica, creando confusión entre profesores y estudiantes.

\section{《 La tarea, entonces, es llegar a}

un equilibrio en el que se puedan

utilizar palabras que ayuden a

conceptualizar y definir la arquitectura

pero que no sean confusas para

el receptor. \)

\section{Conclusión}

Este uso de "arquilenguaje" afirma el planteamiento inicial de la brecha generacional del uso del lenguaje entre profesor y estudiante, así como el cambio en el pensamiento actual entre los jóvenes (enfoque posmoderno), dejando en claro la diferen-

4 Este paradigma presenta la realidad observable a partir de los resultados de la investigación utilizando el método científico. 
cia entre el rigor y rigidez del hacer ciencia (punto de vista positivista), específicamente en el área de las ciencias básicas, en comparación con el diseño que es un proceso creativo (Wong, 2001); creatividad identificada como una habilidad inherente del ser humano, que implica la integración de procesos cognitivos básicos y superiores para construir pensamientos nuevos (Esquivias, 2004).

Surgen de lo anterior preguntas como: ¿se está creando un "embudo" alejando la igualdad y equidad entre profesor y estudiantes, entre profesionista de la arquitectura y su cliente, entre investigadores y no científicos?, ¿será el uso del "arquilenguaje" (lenguaje confuso) el causante del porqué se considera a la Arquitectura hoy en día como promesas incumplidas (Jurado, 2015)?

Es evidente la necesidad de buscar estrategias de retroalimentación en las evaluaciones de proyectos de los estudiantes y contar con un lenguaje común que les ayude a comprender su proceso creativo, hay que estudiar alternativas que respondan al estudiante del mundo posmoderno.

La tarea, entonces, es llegar a un equilibrio en el que se puedan utilizar palabras que ayuden a conceptualizar y definir la Arquitectura, pero que no sean confusas para el receptor: bien entre estudiantes y profesores o arquitectos y sus clientes, pues como ya se ha comentado, por la complejidad de su lenguaje, que aborda en cada término una variada cantidad de elementos, se pone en riesgo la generación de una brecha de comunicación entre los interlocutores, con lo cual se puede generar una confusión que no permita la apropiación de los discursos científicos junto con los métodos utilizados para la enseñanza y el aprendizaje de la disciplina. Aceptar la realidad posmoderna actual y entender la forma de ver el mundo por los jóvenes (incertidumbre, crisis y el mundo en constante cambio) de acuerdo con los pensadores posmodernos, podría reorientar y propiciar estudios para encontrar las respuestas al equilibrio del uso del lenguaje.
Fuentes de consulta

Esquivias, M. (2004). Creatividad: definiciones, antecedentes y aportaciones. Revista Digital Universitaria, 5(1). México: UNAM. Recuperado en mayo de 2016, en: http://www.revista.unam.mx/vol.5/num1/art4/ene_art4.pdf.

Jurado, R. (2015). Arquitectura + educación. Aproximaciones conceptuales. Ciencia $y$ Cultura, (34), 175-186. La Paz, Bolivia: Universidad Católica Boliviana San Pablo. Recuperado en mayo de 2016, en: http://bit. ly/2fkThAn.

Lyotard, J. (1991) La Condición postmoderna: Informe sobre el saber. ( $2^{\mathrm{a}}$ edición). Argentina: Red Editorial Iberoamericana Argentina S.A.

Oh, Y., Ishizaki, S., Gross, M., y Yi-Luen, E. (2013). A theoretical framework of design critiquing in architecture studios. Design Studies, 34(3), 302-325. Recuperado en mayo de 2016, en: http://bit.ly/2f9BxFl.

Richards, W. (2014). I beg your pardon. What. Magazine Architect. The Magazine of the American Institute of Architects, 44-45. USA: AIA-Hanley Wood.

Universidad Autónoma de Aguascalientes. (2015). Modelo Educativo Institucional, en Correo Universitario, No. 15, séptima época, 29 de mayo de 2015. Primera reimpresión. México: UAA. Recuperado en mayo de 2016, en: http://www.uaa.mx/nu/.

Wilkinson, P. (2014). 50 cosas que hay que saber sobre Arquitectura. México: Ariel.

Wong, W. (2001). Fundamentos del Diseño. (3 ${ }^{\mathrm{a}}$ edición). España: G. Gili.

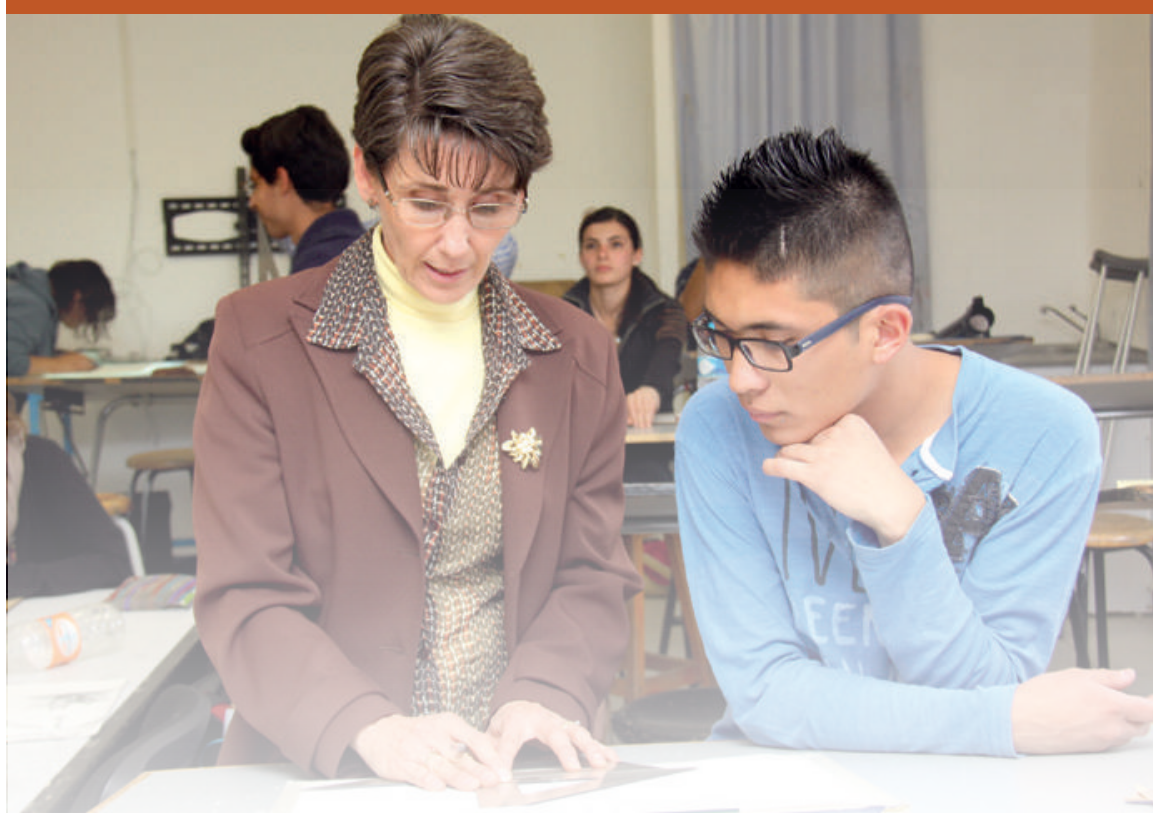

